\title{
Evidence for seasonal changes in population structure of Reed Buntings (Emberiza schoeniclus) in the Lake Neusiedl Region: a stable-isotope approach
}

\author{
Barbara Kofler $^{1}\left[\right.$. Wolfgang Wanek ${ }^{2}$. Christian C. Voigt ${ }^{3} \cdot$ Christian H. Schulze $^{4}$
}

Received: 9 July 2020 / Revised: 17 December 2020 / Accepted: 2 January 2021 / Published online: 22 January 2021

(c) The Author(s) 2021

\begin{abstract}
Migrating species and populations are affected by conditions existing across large geographical scales. The degree to which populations mix at stop-over sites and wintering grounds is variable and can involve important fitness consequences. Thus, the link between breeding and wintering grounds and seasonal shifts in population structure are important to understand population demographics, local adaption and diversification patterns. This work aims to infer migration patterns and population connectivity in the Reed Bunting (Emberiza schoeniclus) community of a Ramsar-designated wetland, Lake Neusiedl, Seewinkel, Austria. Stable isotope markers (hydrogen, $\delta^{2} \mathrm{H}$, carbon, $\delta^{13} \mathrm{C}$ ) in feathers were analyzed to assign individuals to a specific breeding or natal area. Based on the geographic assignment, birds were compared with respect to their ecomorphological traits and their habitat selection (large reed bed versus more open habitat at shore of an alkaline lake) during winter to assess potential ecological differences and possibly associated morphological divergence. Stable isotope data revealed that the local Reed Bunting community undergoes seasonal changes in population structure. Three different populations that vary in their $\delta^{2} \mathrm{H}$ signature and to some extent in morphological characteristics as well as in $\delta^{13} \mathrm{C}$ values were identified. Indications for differential migration related to age and/or sex were additionally found, since males and females as well as first-year birds and adults showed remarkable differences in their traits and feather isotope values. $\delta^{2} \mathrm{H}$ values diverged significantly between these groups in both age and sex classes and birds with highest feather $\delta^{2} \mathrm{H}$ values were considered to represent the local breeding population at Lake Neusiedl and possibly also Reed Buntings from close surroundings. Moreover, this group had the highest $\delta^{13} \mathrm{C}$ values in first-year individuals as well as in adults. In both sex classes, the assignment of Reed Buntings to different populations was ultimately possible due to differences in bill shape with residents being characterized by more massive bills than individuals belonging to populations visiting the study area only during migration or for wintering. During winter, beak shape and feather $\delta^{2} \mathrm{H}$ and $\delta^{13} \mathrm{C}$ values differed significantly between birds caught in the reed stand of Lake Neusiedl and those captured near the salt pan, hence, indicating differential habitat selection among co-occurring populations during winter. These findings suggest that morphological attributes, such as bill shape and size as well as linked adaptations to different food sources play a decisive role for niche segregation among wintering populations. The results provide evidence that different populations mix during migration and during winter at Lake Neusiedl and the extent to which they are specialized to a specific habitat varied.
\end{abstract}

Keywords Stable isotope analysis · Hydrogen isotopes - Carbon isotopes · Geometric morphometrics · Ecomorphology · Habitat selection $\cdot$ Migratory connectivity $\cdot$ Differential migration

Communicated by F. Bairlein.

Supplementary information The online version contains supplementary material available at https://doi.org/10.1007/s1033 6-021-01855-3.

Barbara Kofler

barbara.kofler@univie.ac.at

Extended author information available on the last page of the article 


\section{Zusammenfassung}

Hinweise auf saisonale Veränderungen der Populationsstruktur von Rohrammern (Emberiza schoeniclus) im Neusiedler See-Gebiet durch Stabile Isotope

Populationen weitverbreiteter Zugvogelarten sind in ihren jeweiligen Brut-, Rast- und Überwinterungsgebieten vorherrschenden Umweltbedingung ausgesetzt. Das Ausmaß in dem sich Populationen einzelner Arten in den Überwinterungsgebieten mischen variiert und kann weitreichende Konsequenzen für Überleben und Fitness haben. Daher sind Kenntnisse der Zusammenhänge zwischen Brut- und Überwinterungsgebieten sowie saisonaler Veränderungen der Populationsstruktur wichtige Voraussetzungen für das Verständnis der Demographie von Populationen und ihrer Anpassungen an räumlich-zeitliche Veränderungen der Umweltbedingungen. Die vorliegende Studie soll Erkenntnisse zum Zugverhalten und der Konnektivität von im österreichischen Ramsar-Schutzgebiet Neusiedler See-Seewinkel auftretenden Populationen der Rohrammer (Emberiza schoeniclus) liefern. Die Analyse von Stabilen Isotopen (Wasserstoff, $\delta^{2} \mathrm{H}$, Kohlenstoff, $\delta^{13} \mathrm{C}$ ) in Federn wurde verwendet, um Rückschlüsse auf das Brutgebiet hier rastender und überwinternder Rohrammern zu ziehen. Individuen, welche unterschiedlichen Brutgebieten zugeordnet werden konnten, wurden anschließend hinsichtlich ihrer ökomorphologischen Eigenschaften sowie ihrer Habitatwahl (großes Schilffeld versus offene Uferbereiche einer Salzlacke) während des Winters verglichen, um damit zusammenhängende ökologische und phänotypische Unterschiede zu ermitteln. Die Analyse der stabilen Isotope zeigte saisonale Veränderungen der Populationszusammensetzung am Neusiedler See vorkommender Rohrammern auf. Die $\delta^{2} \mathrm{H}$-Signaturen, zum Teil aber auch morphologische Eigenschaften sowie die $\delta^{13} \mathrm{C}$ Werte, ermöglichten die Differenzierung von Individuen aus drei unterschiedlichen Populationen. Auffallende Unterschiede der morphologischen Eigenschaften und der Feder-Isotopenwerte zwischen Männchen und Weibchen sowie zwischen einjährigen und adulten Individuen deuten auf ein geschlechts- und altersspezifisches Zugverhalten hin. Zwischen den drei festgestellten Populationen waren sowohl Männchen und Weibchen als auch diesjährige und adulte Individuen in ihren $\delta^{2} \mathrm{H}$ Werten verschieden. Rohrammern mit den höchsten $\delta^{2} \mathrm{H}$-Werten wurden der lokalen Brutpopulation des Neusiedler Sees oder den Populationen der näheren Umgebung zugeordnet. Diese Vögel wiesen zudem in beiden Altersklassen die höchsten $\delta^{13} \mathrm{C}$ Werte auf. Individuen beider Geschlechter konnten anhand von Unterschieden der Schnabelform eindeutig einer der drei Populationen zugeordnet werden. Dabei besaßen Rohrammern der lokalen Population die massivsten Schnäbel, während Individuen von Populationen, die nur während der Zugzeit oder im Winter festgestellt wurden, deutlich zierlichere Schnäbel aufwiesen. Signifikante Unterschiede der Schnabelform sowie der $\delta^{2} \mathrm{H}$ - und $\delta^{13} \mathrm{C}-$ Werte zwischen Individuen, welche im Schilfgürtel des Neusiedler Sees bzw. im offenen Uferbereich der Salzlacke überwinterten, geben zudem Hinweise auf eine populationsspezifische Habitatwahl im Überwinterungsgebiet. Dies deutet darauf hin, dass die Schnabelmorphologie, als Hinweis auf die Nutzung verschiedener Nahrungsressourcen, eine entscheidende Rolle für die Einnischung der im Winter im Neusiedler See-Gebiet koexistierenden Rohrammer-Populationen spielt. Die vorliegenden Ergebnisse zeigen, dass sich im Neusiedler See-Gebiet sowohl zu den Zugzeiten als auch im Winter verschiedene Rohrammer-Populationen mischen, welche unterschiedliche Habitate nutzen.

\section{Introduction}

In contrast to animals that spend their entire lives within a local home range, migrant species are affected by environmental conditions existing across larger geographical areas (Arizaga et al. 2015). Migratory species differ in the degree to which individuals from distinct breeding localities mix on different stopover sites and wintering grounds (Chabot et al. 2012; Marra et al. 1998). The link between breeding, stopover and wintering sites can have important fitness consequences for migrating individuals. These consequences are many-fold and include the interaction of direction, distance and duration of migration, and the use of stopover sites and wintering grounds that may vary in quality (Veen et al. 2014). Patterns of connectivity between breeding and wintering grounds of migrating species are; thus, highly significant for their evolution, ecology and conservation (Arizaga et al. 2015; Webster and Marra 2005; Woodworth et al. 2016). Hence, to understand population demographics, local adaptations and causes of diversification, the spatial characteristics (i.e. which populations mix on breeding and on wintering grounds) and the strength of migratory connectivity must be quantified (Chabot et al. 2012; Webster et al. 2002).

Migratory connectivity is conceptually of particular interest in habitat specialists, which occupy narrow ecological niches and utilize similar habitat types all year round. As these species have strict habitat requirements, they are potentially vulnerable to changes in environmental conditions and land use that reduce the availability of suitable habitats (Briedis et al. 2016).

Although, globally over $85 \%$ of wetlands have already been lost, they are still being drained and have yet come under considerable pressure (IPBES 2019). Population trends of reed-dwelling bird species are closely tied to the condition and the state of maintenance of those habitats. As 
habitat fragmentation continues, the conservation of remaining wetlands has become crucial, especially to a number of highly sensitive or specialized species, whose occurrences experienced drastic decline in the recent years, e.g. the Water Rail (Rallus aquaticus) (Brambilla et al. 2012), the Little Bittern (Ixobrychus minutus) and the Great Reed Warbler (Acrocephalus arundinaceus) (Benassi et al. 2009) as well as the Ferruginous Duck (Aythya nyroca) (BirdLife International 2020). This also applies to the Reed Bunting (Emberiza schoeniclus) (Pasinelli and Schiegg 2012; Musilová et al. 2014), which is primarily associated with wetlands (Glutz von Blotzheim and Bauer 1997). The Reed Bunting is a Palearctic short- to medium-distance migratory songbird, whose distribution is wide ranging and covers most of Europe and large parts of temperate and northern Asia (Byers et al. 2010).

Based on the differences in bill size, body size, plumage colour and song, over 30 Reed Bunting subspecies have historically been described (Glutz von Blotzheim and Bauer 1997; Vaurie 1956, 1958). However, the phenotypic divergence between populations is complex and often largely clinal (Neto et al. 2013). Specifically, there is a latitudinal gradient of increasing beak size and body size towards the south; additionally, there is a longitudinal gradient of increasing beak size towards the east in the southern part of the distribution range. Furthermore, a longitudinal gradient exists with respect to plumage, which is darkest in the west and becomes increasingly paler towards the east (Neto et al. 2013; Vaurie 1956). Although southern populations are resident, those further north at least partially migrate towards various directions over short and medium distances; consequently, during winter thin-billed individuals often co-occur with thick-billed birds (Prŷs-Jones 1984; Neto et al. 2013).

In Austria, the Reed Bunting is a common species and present year-round. Especially in the Lake Neusiedl region (Dvorak et al. 1993), which harbours the second largest contiguous reed stand (Phragmites australis) in Europe, it can be observed regularly. The Austrian part of the reed bed extends over $103 \mathrm{~km}^{2}$ and is inhabited by an estimated number of 1877 (1460-2399 SD) breeding pairs (BirdLife Austria unpubl.), the by far largest breeding population in Austria. However, much higher abundances than during the breeding season are usually recorded during winter (www. ornitho.at/BirdLife Österreich; BirdLife Austria unpublished). This demonstrates the significance of the region as wintering ground for Reed Buntings, though the catchment area is still not known. Hence, the main interest of this study on Reed Buntings at Lake Neusiedl (Eastern Austria) was to assess the local community composition during migration times and during winter. Stable isotope markers (hydrogen, $\delta^{2} \mathrm{H}$, carbon, $\delta^{13} \mathrm{C}$ ) from feathers were used to assign individuals to groups with different geographic provenance in order to unravel movement patterns of Reed Buntings that occur at Lake Neusiedl. Moreover, geographic variation in plumage and morphological characters can additionally be used to assess directly migratory connectivity whenever phenotypes are geographically segregated within either their breeding or non-breeding range (Webster et al. 2002). As afore mentioned, such is the case in Reed Bunting subspecies. Ecomorphological traits (e.g. bill shape and bill size, wing shape) were used to test for differences between groups of distinct geographic origin and to characterize phenotypes of those groups. Morphological traits were assessed using geometric morphometrics and linear measurements.

In Western European Reed Buntings, migratory and foraging behaviour have been identified as significant selection pressures, shaping the phenotypic diversification among them (Neto et al. 2013). We hypothesize that different populations that vary in phenotype effectively coexist at Lake Neusiedl during winter based on the habitat partitioning resulting from disparate food preferences. Therefore, we tested for potential differences in habitat selection among wintering individuals from distinct breeding/natal areas that diverge in morphological traits. During winter, southern Reed Buntings with thicker bills, which may belong to the local breeding population or originate from adjacent breeding areas, should preferentially feed on dormant stages of insects hiding inside the hollow reed stems. In contrast, thinbilled birds from northern populations may feed predominantly on small seeds (Neto et al. 2013). Hence, we predict that in winter birds with thicker bills may predominantly utilize the reed belt of Lake Neusiedl, while thinner-billed individuals may be more abundant in open areas such as the shorelines of soda pans with a higher availability of seeds provided by herbaceous plants.

\section{Methods}

\section{Ethics statement}

All federal permits for the data collection, and the use of feather material was issued by the Austrian Federal Ministry of Education, Science and Research and the Department for Nature Conservation of the provincial government of Burgenland. The capture and ringing of birds followed standard protocols and birds were released unharmed on site.

\section{Study sites and mist netting}

In the course of one year, from February 2017 until February 2018, Reed Buntings $(n=372)$ were caught at the eastern shore of Lake Neusiedl in Illmitz (mean annual precipitation $=$ approximately $600 \mathrm{~mm}$, mean annual temperature $=10.1^{\circ} \mathrm{C}$, elevation $=117 \mathrm{~m}$ a.s.l. $)$. The main field site (reed) was located along a dam (west-east orientation) 
that leads through an approximately $1 \mathrm{~km}$ wide reed bed at the eastern shore of the lake $\left(47.76938^{\circ} \mathrm{N}, 16.75636^{\circ}\right.$ E). A second site was located east of the lake in a more open habitat at the shore of an alkaline lake (salt pan), with less extensive reed stands, abundant halophytic Chenopodiaceae species and early successional vegetation with oleaster and other shrubs, close to some wine yards $\left(47.80746^{\circ} \mathrm{N}\right.$, $16.79040^{\circ} \mathrm{E}$ ). This second field site was only studied during winter in order to assess whether different populations or morphotypes that potentially mix in this wintering area are locally segregated between microhabitats.

Birds were captured with mist-nets, during winter they were additionally attracted using a playback mix of song records of all relevant subspecies to increase the otherwise low capture rates. Each bird was marked with a metal ring, and the sex and age were determined using published criteria (Jenni and Winkler 1994). Wing length (maximum chord) and the length of P8 were measured with a metal ruler to the nearest $0.5 \mathrm{~mm}$. Bill depth (at nostrils), bill length (to skull) and tarsus were measured with plastic callipers to the nearest $0.1 \mathrm{~mm}$.

\section{Stable isotope analysis}

For stable isotope analysis, we collected a sample of each bird's fifth secondary flight feather. With regard to the species-specific moulting patterns (Jenni and Winkler 1994), the fifth secondary was determined to reflect the stable isotope signature of the local food web of the breeding or natal area of the birds. Adults undergo their post-breeding complete molt between mid of July and end of September. As migration of adults even in their northernmost breeding areas usually start as late as in the second third of September (Glutz von Blotzheim and Bauer 1997), the $5^{\text {th }}$ secondary should be already molted in the vast majority of adult birds before leaving their breeding grounds. Collected feathers were stored separately in clean paper envelopes for later isotope analysis. The samples were then randomly subsampled to maintain enough data when subdividing the dataset into sex, age and seasonal classes. Stable isotope analyses were performed at the stable isotope laboratory of the Leibniz Institute for Zoo and Wildlife Research (IZW, Berlin, Germany). Prior to isotope-ratio mass spectrometry, the samples were cleaned for $24 \mathrm{~h}$ in a $2: 1$ chloroform:methanol solution to remove surface contaminants and oils. Then, the samples were dried in a drying oven for $24 \mathrm{~h}$ at $50{ }^{\circ} \mathrm{C}$. For stable carbon isotope analysis, $0.3-0.4 \mathrm{mg}$ of cleaned feather vanes was placed into tin capsules. A Delta V-Advantage stable isotope ratio mass spectrometer (Thermo Fisher Scientific, Bremen, Germany), connected to a Flash EA 1112 Series (Thermo Fisher Scientific) elemental analyzer in continuous mode, was used to measure stable carbon isotopes. The stable isotope ratios were calculated as per mil (\%o) deviations from the ratios of the international standard, Vienna Pee Dee Belemnite (V-PDB) and expressed in the delta $(\delta)$ notation. The laboratory standard of known ${ }^{13} \mathrm{C} /{ }^{12} \mathrm{C}$ ratio, tyrosine, was used in conjunction with other international standards (NBS 19, NBS 22, USGS 24 and L-SVEC). Measurement precision was estimated to be $\pm 2.1 \%$ (one standard deviation).

For stable hydrogen isotope analysis, $0.27 \pm 0.01 \mathrm{mg}$ of cleaned feather vanes was placed into silver capsules and left open (IVA Analysetechnik e.K., Meerbusch, Germany). When loading the 96 well microtitre plate, we added capsules with reference keratin material (sheep, goat and human). Then, the filled microtitre plate was placed open at least for $24 \mathrm{~h}$ at $50{ }^{\circ} \mathrm{C}$ in a drying oven to speed up equilibration and remove extra moisture. After loading the samples into a Zero Blank autosampler (Costech Analytical Technologies Inc., Cernusco sul Naviglio, Italy) they were flushed with chemically pure helium for $1 \mathrm{~h}$. Chemically pure helium was also used as carrier gas. Subsequently, samples and standards were pyrolysed at $1350{ }^{\circ} \mathrm{C}$ in a high-temperature elemental analyzer (HEKAtech $\mathrm{GmbH}$ Analysentechnik, Wegberg, Germany) with a silicon carbide tube filled halfway with glassy carbon chops and a carbon/ water trap. $\mathrm{H}_{2}, \mathrm{~N}_{2}$ and $\mathrm{CO}$ were separated at $80{ }^{\circ} \mathrm{C}$ (HTO Element Analyzer, HEKAtech GmbH Analysentechnik) and hydrogen stable isotope ratios were measured with a Delta $\mathrm{V}$ Advantage (Thermo Fisher Scientific). The stable hydrogen isotope ratios were expressed in the delta notation as per mil (\%o) deviations from the international standard V-SMOW. Keratin standards were previously calibrated to the USGS42 standard (Voigt and Lehnert 2018): $\delta^{2} \mathrm{H}=-111.65 \%$ SWE-SHE (powdered wool from sheep, Sweden), -61.54\%。 ESP-SHE (sheep, Spain), -26.44\% AFR-GOAT (goat, Tanzania) and $-72.9 \pm 2.2 \%$ o USGS42 (human hair, Tibet). The analytical precision of repeated measurements of keratin standards equalled $\pm 1.6 \%$ (one standard deviation). We used these keratin standards to determine the stable isotope ratios of non-exchangeable hydrogen following Voigt and Lehnert (2018).

\section{Geometric morphometrics}

For geometric morphometric analysis a photograph of the bill in profile $(n=109)$ was captured on a millimetre grid (Nikon D7000 ${ }^{\circledR}$, Nikon, Melville, New York, USA). Before analysis, the photographs were edited in Adobe Photoshop CS2. A tps file was built from each image using tpsUtil version 1.74 (Rohlf 2016a). TpsDig2 version 2.30 (Rohlf 2016b) was then used to place seven landmarks (discrete homologous points) and eight semi-landmarks (points on a curve, determined by extrinsic criteria) (Zelditch et al. 2004) on each beak image. The semi-landmarks were placed by 
reference to a standardized grid superimposed onto each image, as detailed in Foster et al. (2008).

To remove non-shape variation, the landmark coordinates were rotated, translated and scaled through Generalized orthogonal least-squares Procrustes Analysis (GPA) as a 'standardization' step implemented in the R package geomorph (Adams et al. 2018). The grand mean was calculated (i.e. the consensus of all specimens) and shape variables were then generated (Bookstein 1997). The centroid size (Csize) was computed as the square root of the sum of the squares of the distances from all landmarks to their centroid (Bookstein 1991).

\section{Wing shape}

For each bird, a digital picture (Nikon D7000 camera ${ }^{\circledR}$, Nikon, Melville, New York, USA) was taken of its fully extended right wing. For each individual, all measurements were performed on the same picture. A millimetre grid was placed in the background to provide a scale. The length of the primaries was digitally measured as described in Vanhooydonck et al. (2009), using the image processing program ImageJ (Schneider et al. 2012). The measured length of the primary feathers $1-8$ was then used to calculate wing pointedness (C2-index) and convexity (C3-index) according to Lockwood et al. (1998). Higher values of C2 relate to a relatively more rounded wing, whilst higher values of $\mathrm{C} 3$ correspond to a more convex wing (Arizaga et al. 2006).

\section{Statistical analyses}

Statistical analyses were conducted in R 3.5.2 (R Core Team 2018). Unless specified otherwise in the methods, required packages for this analysis included car (Fox and Weisberg 2011), ggpubr (Kassambara 2019), geomorph (Adams et al. 2018), stats (R core Team 2018), IsoriX (Courtiol et al. 2019) and densityClust (Pedersen et al. 2017). Statistical significance was accepted at $p<0.05$.

First, the relationship between $\delta^{2} \mathrm{H}$ and $\delta^{13} \mathrm{C}$ values of feathers was evaluated with Spearman's rank correlation. Feather $\delta^{2} \mathrm{H}$ and $\delta^{13} \mathrm{C}$ values were then used to perform density-based cluster analysis provided by the R-package densityClust (Pedersen et al. 2017). The assigned cluster membership of all observations $(n=110)$ was extracted and used as grouping factor in univariate and multivariate analysis.

To estimate the geographic provenance of the sampled feathers (moulting locality/natal origin), the R-package IsoriX (Courtiol et al. 2019) was used. A spatial mixed model was calculated by predicting a $\delta^{2} \mathrm{H}$ isoscape based on the rainfall $\delta^{2} \mathrm{H}_{\mathrm{p}}$ values (corrected for altitudinal changes) from the Global Network of Isotopes in Precipitation (GNIP). All available precipitation data from June until October, when Reed Buntings undergo their complete or post-juvenile moult (Jenni and Winkler 2007), were used. To define the relationship between the feather $\delta^{2} \mathrm{H}_{\mathrm{f}}$ values and rainfall isotope $\delta 2 \mathrm{H}_{\mathrm{p}}$ values, a transfer equation $\left(\delta^{2} \mathrm{H}_{\mathrm{f}}=1.28\right.$, $\delta^{2} \mathrm{H}_{\text {ISOSCAPE }}{ }^{-10.29)}$ based on $\delta^{2} \mathrm{H}_{\mathrm{f}}$ values of Eurasian Reed Warblers (Acrocephalus scirpaceus) from known location that is reported in Procházka et al. (2013) was applied. To fit the calibration function, IsoriX uses a linear mixedeffects model (LMM) that considers the prediction variance, which varies spatially, as well as the prediction covariances between predicted isotope values across the isoscape (for details see Courtiol et al. (2019). Based on this calibration model, the geographic assignment of Reed Bunting feathers of unknown origin was performed and a probability map of geographic origin was created.

Statistical analysis and visualization of beak shape variation was performed using the $\mathrm{R}$ package geomorph (Adams et al. 2018). These data were then used in multivariate analysis to assess beak shape variation. A covariance matrix from GPA-aligned Procrustes coordinates was used to perform a number of statistical tests to appraise beak-shape differences in predefined geographical groups (clusters 1-3). However, GPA does not take account of the relationship between size and shape. Therefore, an allometric regression was performed using Procrustes ANOVA with permutation procedure in order to assess the association between log centroid size and shape variables. Furthermore, Procrustes ANOVAs were calculated to assess the relative amount of shape and size variation attributable to the categorical predictor (cluster), with age and sex as covariates. In these analyses, significance was evaluated with a residual randomization permutation procedure of 1000 iterations. A principal component analysis (PCA) of shape variation was performed to visualize morphological differences among groups in a two-dimensional plot of tangent space for a set of Procrustes shape variables (PC1 and PC2). Deformation grids were additionally computed to display the shape of specimens at the end of the range of $\mathrm{PC} 1$ and $\mathrm{PC} 2$.

Linear measurements of beak shape were reduced to one variable, which represents an overall bill shape index (bill shape IND $_{\text {, }}$, by dividing bill depth by bill length. Overall body size, estimated as the first principal component of an analysis including the variables tarsus and wing length ( $\mathrm{PC}_{\text {BODY SIZE }} 71.3 \%$ explained variance), was included as covariate in linear regression models to test for relationships between body size and linear bill measurements. Season was used as additional grouping variable, with groups being defined according to the Reed Buntings' phenology at these latitudes, as referred in Csörgő et al. (2009) and Glutz von Blotzheim and Bauer (1997), as spring (16 Feb-30 Apr), summer (1 May-11 Sep), autumn (12 Sep-18 Nov) and winter (19 Nov-16 Feb). Further, age classes were reduced to two groups (first year, adult). Undetermined individuals were not considered in the analysis. 
A data subset $(n=66)$ containing all observations from winter $\left(\right.$ data $\left._{\text {WINTER }}\right)$ was used to test for differences of morphological traits as well as for variation in feather stable isotope ratios of wintering Reed Buntings that were caught at different sampling locations (reed, salt pan).

Parametric (one-way ANOVA and Student's $t$ test) and non-parametric (Wilcoxon-Mann-Whitney test, Kruskal-Wallis test) univariate tests were applied in order to evaluate the effects of age, sex, habitat and cluster on each of the morphological traits and feather stable isotope values. Whenever there were significant differences between the two sex and age classes, tests were performed for males and females or for adults and first-year individuals separately. As post hoc analysis, Tukey's tests or Dunn's tests with Benjamini-Hochberg adjustment (1995) were used.

\section{Results}

Spearman's rank correlation revealed a strong positive linear relationship between feather $\delta^{2} \mathrm{H}$ and $\delta^{13} \mathrm{C}$ values (first year $R=0.73, p<0.001$; adult $R=0.52, p<0.001$ ). Thus, not only $\delta^{2} \mathrm{H}$ but also $\delta^{13} \mathrm{C}$ values were considered to contain information on the geographic origin of the captured birds. Subsequently, we calculated a distance matrix based on the stable hydrogen and carbon isotope values, which led to three separate isotopic clusters (distance cut off: 0.169, threshold for local density when detecting cluster peaks $\rho=3.5$, threshold for minimum distance to higher density when detecting cluster peaks $\delta=0.3$ ). A total of 50 individuals was assigned to the cores of the clusters (core) and 60 individuals were assigned as halo, i.e. points with lower density (Supplementary file, App. 1). The halo-observations were kept in the dataset for further analysis. The dataset was filtered for core assignments only for the visualization of relative frequencies of clusters per season (Fig. 1). Birds from the first two clusters were present at Lake Neusiedl only in spring. All core assignments from summer were belonging to cluster 1 and during autumn and winter individuals

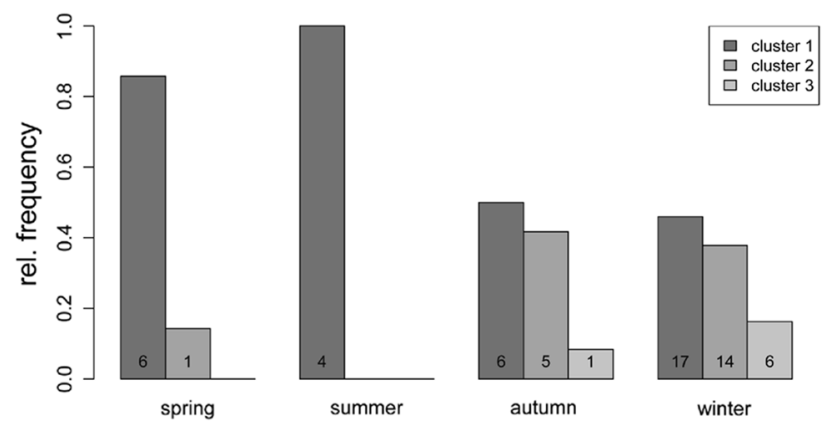

Fig. 1 Relative frequencies of Reed Bunting clusters per season (numbers refer to individuals belonging to the cluster cores) of clusters 2 and 3 were encountered with distinct relative frequencies (Fig. 1).

\section{Stable isotopes and morphological traits}

$\delta^{2} \mathrm{H}$ values differed between age and sex classes. One-way ANOVAs and following post hoc tests revealed highly significant differences between all three clusters in both sex and age classes (Online Resource 1, Table 1). Feathers from birds of cluster 1 had the highest $\delta^{2} \mathrm{H}$ values and feathers from cluster 3 the lowest (Fig. 2). Regarding feather $\delta^{13} \mathrm{C}$ values, cluster 1 differed significantly from clusters 2 and 3 (Online Resource 1, Table 1), with first-year birds and adults having the highest $\delta^{13} \mathrm{C}$ values in both clusters (Fig. 3).

In both sex classes, Reed Buntings of cluster 1 had the thickest bills and the lowest bill shape ${ }_{\text {IND }}$, i.e. more massive bills in general. Individuals from cluster 3 showed a tendency to have the smallest beaks (Online Resource 1, Table 1; Fig. 4).

When looking at the two Lockwood indices C2 and C3, birds of cluster 1 differed from those of cluster 2 (Online Resource 1, Table 1; Fig. 5). However, when analysing Lockwood C2 for sex classes separately, we observed contrasting results. Females from cluster 3 were different from those of cluster 2 and males that belonged to cluster 1 differed from males which were assigned to the second cluster. Birds of clusters 1 and 2, instead, did not differ significantly. The difference in wing convexity (Lockwood C3) was not consistent when analysing sex categories independently (Online Resource 1, Table 1).

During winter the birds caught in the reed stand of Lake Neusiedl differed significantly with respect to their bill shape $_{\text {IND }}(p=0.03)$ and bill depth $(p=0.009)$ from those captured near the salt pan. When analysing bill depth for the two sex classes separately, we detected a difference only in males $p=0.008)$. Moreover, birds form the two habitats differed in their feather $\delta^{2} \mathrm{H}(p=0.01)$ and $\delta^{13} \mathrm{C}$ values $(p<0.001)$. Birds at the salt lake had thinner bills and were lower in $\delta^{2} \mathrm{H}$ and $\delta^{13} \mathrm{C}$ (Table 1; Fig. 6).

\section{Geometric morphometrics}

We did not observe differences in (log) centroid size among clusters and age and sex classes in the overall dataset (Online Resource 1, Tab. 2 top panel). Allometric regressions revealed a small size related effect in shape variation among clusters and cluster with age as covariate, which explained only 5\% (cluster) and 3\% (cluster:age) of the total variation (Online Resource 1, Tab. 2 bottom panel). Beak shapes differed significantly between clusters $(p=0.002)$ and the interaction between cluster and age had also a significant effect on beak shape variation $(p=0.034)$ (Online Resource 1, Tab. 2 middle panel). Procrustes ANOVA on shape with 
Fig. 2 Boxplots of stable hydrogen isotope values by cluster, age class (a adult, b first year) and sex class (c male, $\mathbf{d}$ female); statistical significance levels from pairwise comparisons (post hoc tests) are displayed above brackets $[p>0.05$ (ns), $p<0.05(*), p<0.01$ (**), $p<0.001(* * *), p<0.0001$ $(* * * *)]$
Fig. 3 Boxplots of stable carbon isotope ratios of different clusters and age classes (a adult, b first year)
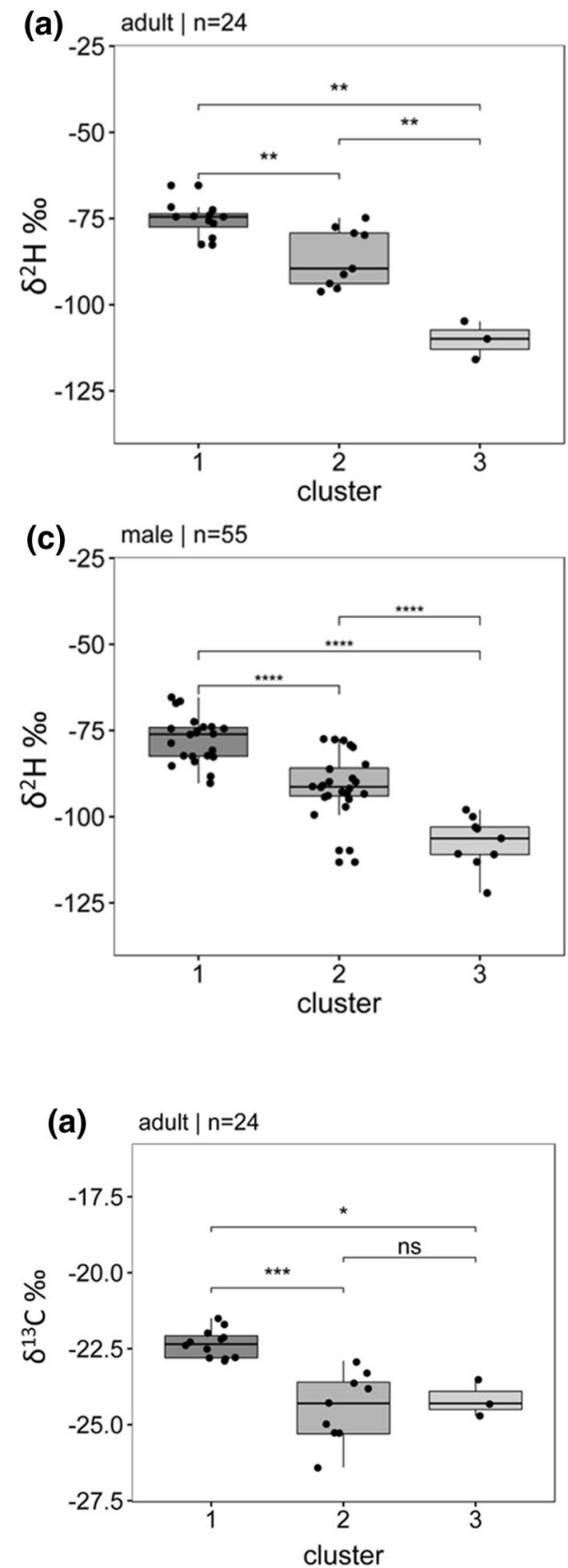
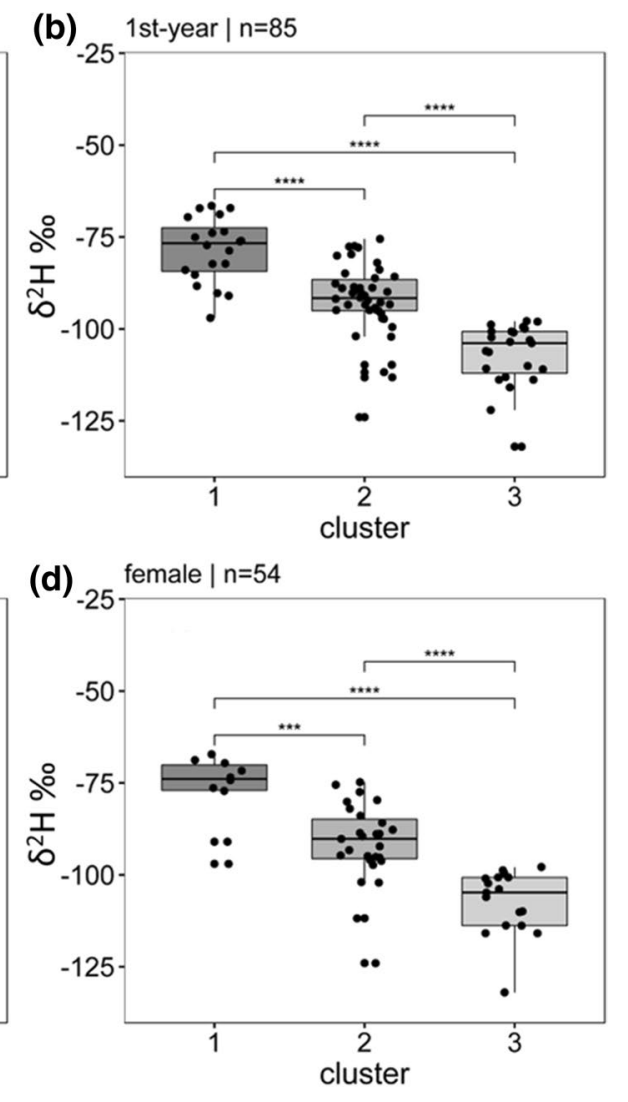

(d)



cluster as predictor and age as covariate was highly significant $(F=2.177, p=0.001)$ and post hoc analysis indicated shape differences between cluster 1 and the other two clusters. We did not observe significant beak shape divergence between birds of clusters 2 and 3 . The visualization of shape differentiation in the principal component plot was grouped by cluster and age classes. The first principal component of shape variation (PC1) explained $27.5 \%$, while PC2 explained $24.2 \%$ of the total variation (Fig. 7 a).

Comparisons of the data WINTER $_{\text {beak }}(\log )$ centroid size indicated no difference in size among the habitat types with age and sex as covariates (Online Resource 1, Tab. 3 top panel). Allometric regression revealed a small size related effect on shape variation associated with habitat $(p=0.001)$ as well as with $(\log )$ centroid size and sex ( $p=0.023$ ) (Online Resource 1, Tab. 3 bottom panel). Approximately $10 \%$ of the beak shape variation of wintering Reed Buntings could be explained by the different habitats they were captured at $(p=0.001)$ (Online Resource 1, Tab. 3 middle panel). Procrustes ANOVA on shape variance returned a significant effect $(F=3.133$, $p=0.001$ ) associated with habitat as predictor and age as covariate. This shows a clear divergence in beak shape among Reed Buntings caught at different habitats during winter. The first principal component of shape variation (PC1) explained $31.4 \%$, while PC2 explained $21.4 \%$ of the 

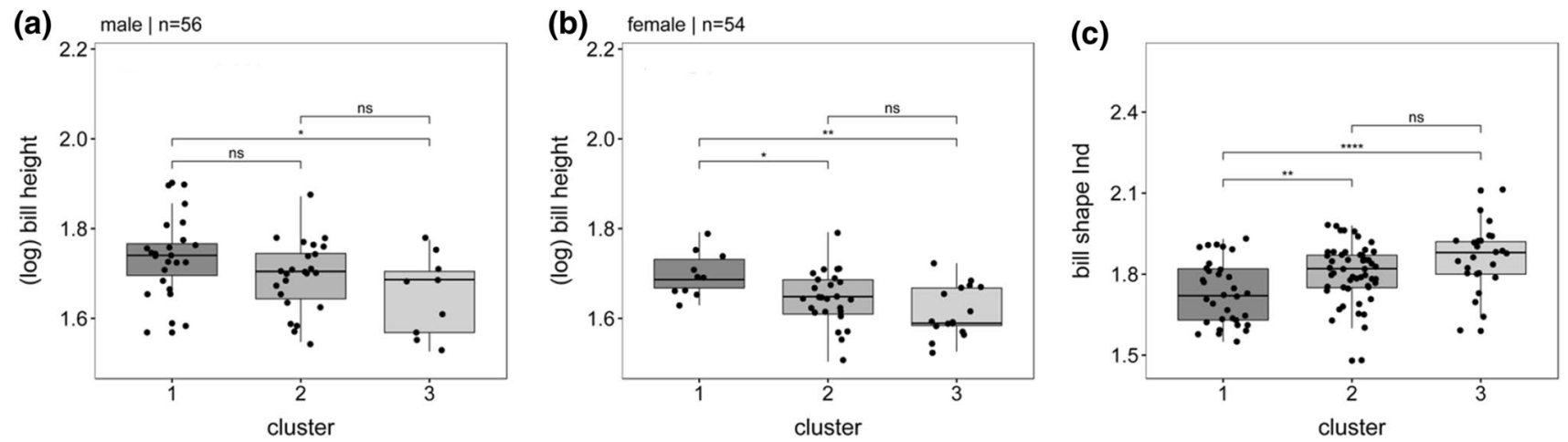

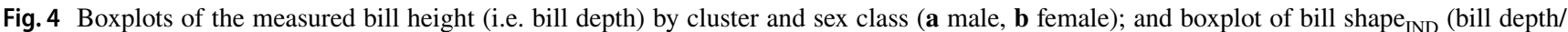
bill length) of different clusters (c)

Fig. 5 Boxplots of Lockwood indices $(\mathrm{C} 2, \mathrm{C} 3)$ of different clusters

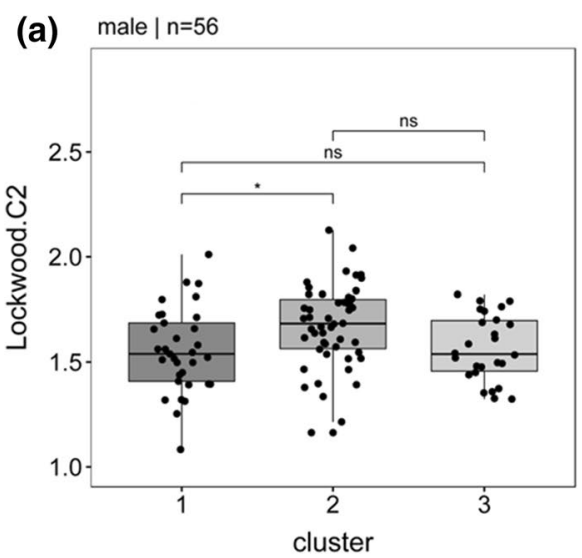



Table 1 Results from Students $t$ tests and Man-Whitney $U$ test comparing stable isotope ratios and morphological variables among the two different habitat types (reed and salt pan)

\begin{tabular}{|c|c|c|c|c|c|}
\hline \multirow[t]{2}{*}{ Variable } & \multicolumn{3}{|c|}{$t$ test $\sim$ habitat } & \multicolumn{2}{|c|}{$\begin{array}{l}\text { Man-Whitney } U \\
\text { test } \sim \text { habitat }\end{array}$} \\
\hline & $t$ & $d f$ & $p$ & $W$ & $p$ \\
\hline $\begin{array}{l}\text { d2H (Saskatoon. } \\
\text { kstd) }\end{array}$ & 2.65 & 57.51 & $0.01 *$ & & \\
\hline $\mathrm{d} 13 \mathrm{C}$ & & & & 743 & $<0.001 * * *$ \\
\hline Bill height & 2.756 & 38.642 & $0.009 * *$ & & \\
\hline Bill height/male & 2.953 & 18.87 & $0.008 * *$ & & \\
\hline Bill heightlfemale & 1.437 & 14.952 & 0.171 & & \\
\hline Bill shape Ind & -2.253 & 38.406 & $0.03 *$ & & \\
\hline Lockwood.C2 & 1.484 & 53.081 & 0.144 & & \\
\hline Lockwood.C3 & -0.928 & 55.809 & 0.357 & & \\
\hline Wing & -0.917 & 57.284 & 0.3626 & & \\
\hline Body size PC1 & 0.385 & 44.938 & 0.702 & & \\
\hline
\end{tabular}

total variation (Fig. 7b). Birds from cluster 1 were only caught in the reed bed of the Lake.

\section{Geographic provenance of reed buntings}

Relating the $\delta^{2} \mathrm{H}$ values of sampled feathers to the predicted $\delta^{2} \mathrm{H}$ isoscape shows clear differences in the likelihood of spatial origin of individuals from different clusters identified by stable isotope analysis. The group assignment indicates the southernmost distribution for cluster 1 reaching from southern Great Britain towards south and southeastern Europe, while cluster 3 showed the most northern projected region of geographic origin that covers south Scandinavia, the Baltic States and north-eastern Europe. Cluster 2 was assigned to a geographic provenance along a latitudinal band ranging from central to eastern Europe (Fig. 8). 

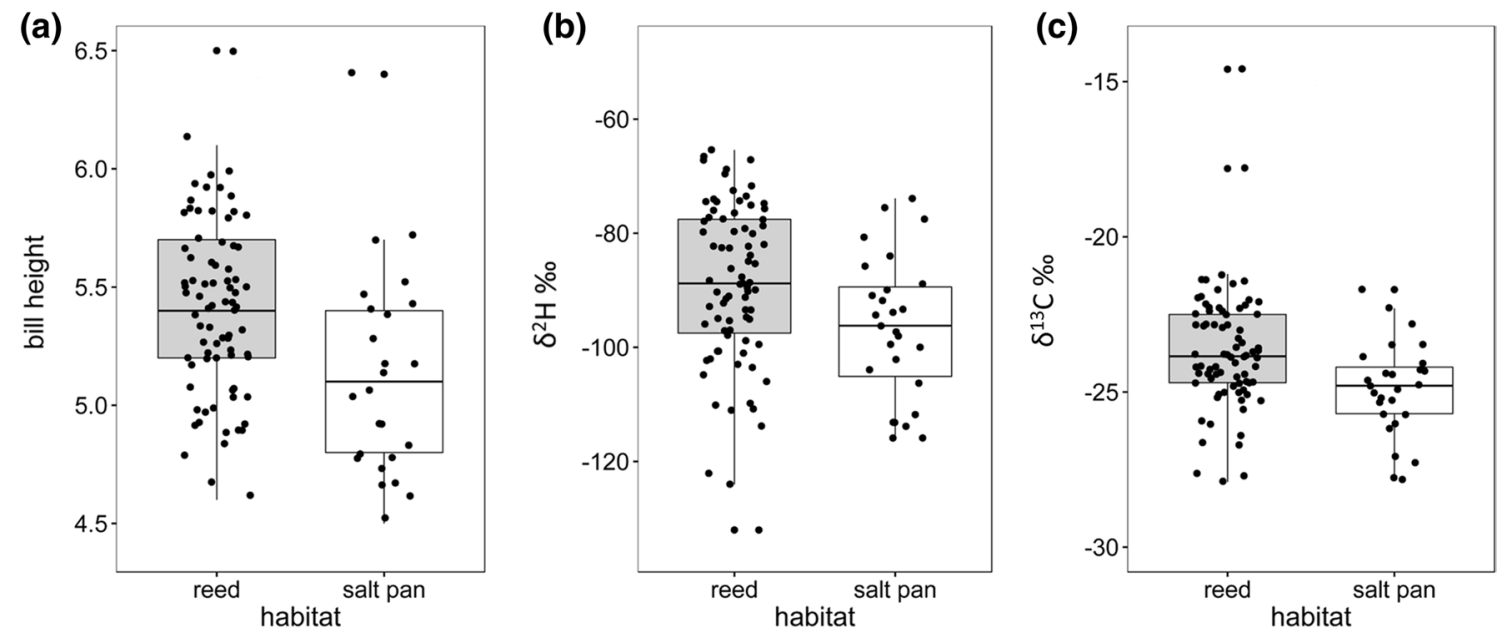

Fig. 6 Boxplots of bill height and stable hydrogen and carbon isotopes at different habitat types during winter (reed, salt pan)

(a)
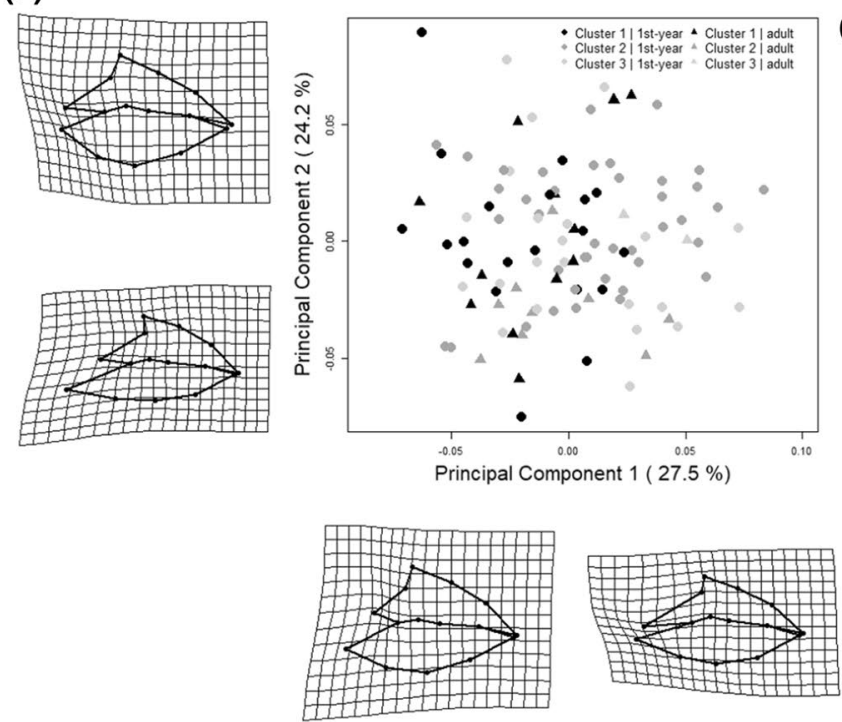

(b)
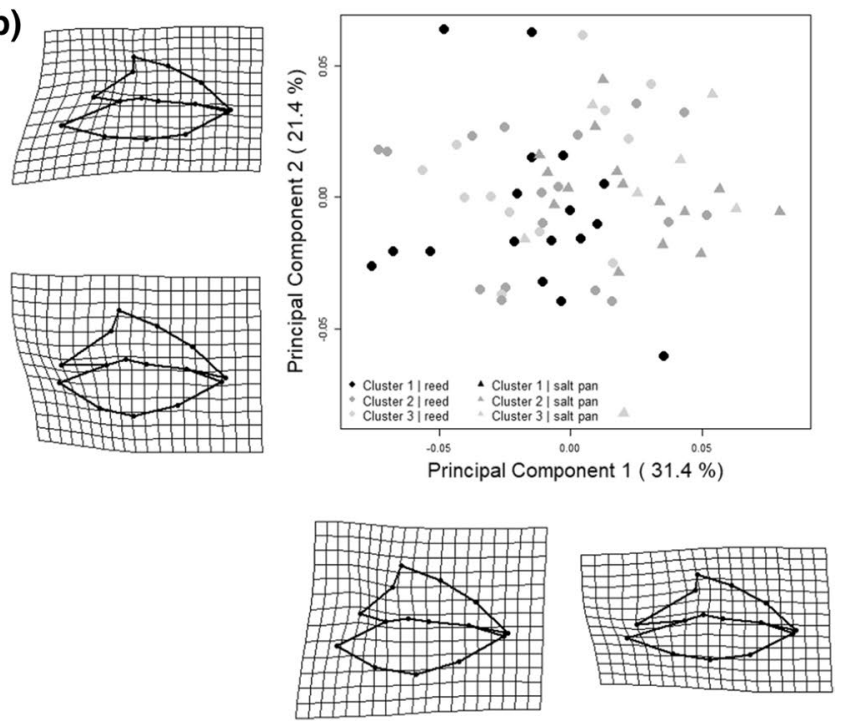

Fig. 7 Morphological difference among groups (a cluster and age class; b cluster and habitat type) plotted in a two-dimensional plot of tangent space of Procrustes shape variables (PC1 and PC2). Deforma-

\section{Discussion}

Group comparisons of hydrogen and carbon stable isotope ratios showed that the applied clustering method was powerful to separate groups that differ in their isotopic signature, especially in the case of $\delta^{2} \mathrm{H}$. Therefore, it can be considered that the specific clusters indicate groups of different geographic provenance. Cluster 1 was least depleted in deuterium and represents local breeding population and possibly also Reed Buntings from adjacent breeding areas, which cannot be distinguished by the applied methods. We tion grids display the shape of specimens at the end of the range of the principal component axes

herein refer to this cluster as local birds. Moreover, individuals assigned to cluster 1 were encountered throughout the whole year, indicating that at least part of the local population stays resident year-round at Lake Neusiedl. In addition, a first autumn migration wave brought individuals from clusters 2 and 3 , while cluster 2 in comparison to cluster 3 reached a higher relative abundance within the autumn Reed Bunting assemblage. These findings indicate that first migrants in autumn arrive from comparatively shorter distances, which corresponds to specifications on the Hungarian Reed Bunting population provided by Csörgő et al. (2009). Later, during winter, observations 


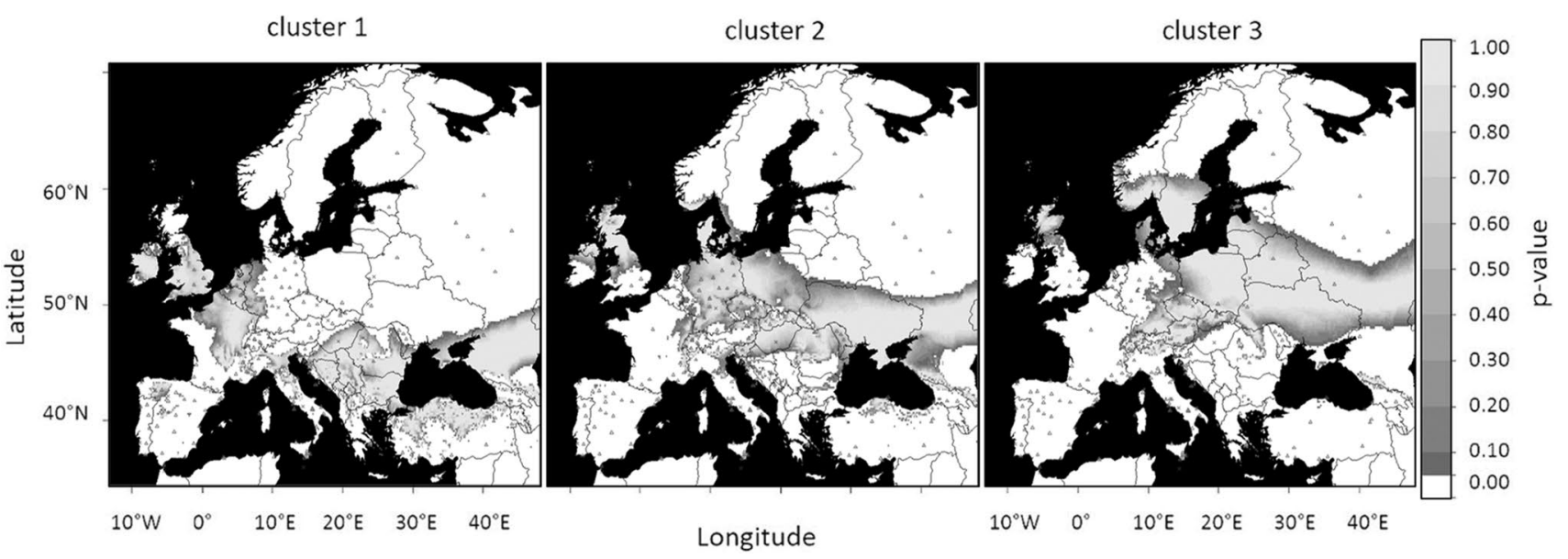

Fig. 8 Geographic assignment of core individuals of each cluster (triangles indicate sampling locations of the sources; crosses indicate the sampling locations of the calibration samples), significant $p$ values are strong evidence that the sample does NOT come from the candidate location

from cluster 3 , which comprises individuals with lowest feather $\delta^{2} \mathrm{H}$ ratios (furthest north), became relatively more abundant. Interestingly, adult males that overwintered at Lake Neusiedl were only assigned to cluster 1 and 2. In contrast, no adult female of the local population was observed within the Reed Bunting assemblage during winter. This pattern could simply be an artefact of overall low numbers of adults that were caught during winter and were assigned to the cluster cores. Another possible explanation could be differential age and sex specific wintering distributions among individuals of the species. In birds, spatial segregation during the non-breeding period is a common phenomenon, in which distances travelled differ between portions of a population (Arizaga et al. 2015; Cristol et al. 1999). By spending the non-breeding season in separate areas, different members of a population may face divergent factors that potentially affect survivorship. Therefore, differential migration can have considerable implications for the conservation of migratory birds (Cristol et al. 1999).

Stable carbon isotope ratios in animal tissues closely reflect those of their diet (Körner et al. 1991; Hobson 1999; Rubenstein and Hobson 2004; Brattström et al. 2008) and undergo fairly limited changes (generally increase by $0-1 \%$ ) between trophic levels or from diet to consumers (Inger and Bearhop 2008). More importantly, $\delta^{13} \mathrm{C}$ values of primary producers tend to respond to a number of environmental variables (e.g. Hobson and Wassenaar 1999; Staddon 2004; Brattström et al. 2008; Lajtha and Marshall 1994) and photosynthetic processes of primary producers (Inger and Bearhop 2008; Lajtha and Marshall 1994; Inger and Bearhop 2008; Hobson 2019). Feather $\delta^{13} \mathrm{C}$ values of cluster 1 differed significantly from the other two clusters. This variation in $\delta^{13} \mathrm{C}$ could be linked to the different geographic origin, to differential habitat use and/or an altered preference of food sources among clusters during feather growth. Although a positive relationship between $\delta^{2} \mathrm{H}$ and $\delta^{13} \mathrm{C}$ signatures of Reed Bunting feathers was found and cluster 1, which showed the southernmost breeding distribution, was least depleted in ${ }^{13} \mathrm{C}$, further investigations that include measurements on potential food sources and foraging ecology during feather growth are clearly required to shed more light onto this pattern.

Reed Buntings that belonged to different clusters did not only show differences in their stable isotope ratios but also in their morphological traits, such as in bill depth, bill shape and wing shape. The local population differed in bill depth and bill shape from northern migrants and wing shape variation was most remarkable between cluster 2 and the other two clusters. It is well-known that morphological traits such as bill, wing and tarsus length are shaped by the behaviour and the ecological niche of a species, allowing to make inferences about these niches (Dawideit et al. 2009). Bill shape variation is expected to be subject to strong natural selection for feeding (e.g. Grant 1985; Dawideit et al. 2009) and can further be linked to climatic conditions, to sexual selection or to biogeographic patterns (Neto et al. 2016). Although Reed Buntings are mainly insectivorous during spring and summer, during winter thin-billed birds feed almost exclusively on small seeds, whereas thick-billed subspecies seem to feed on dormant insects located inside the reed stems (Neto et al. 2016). For instance, the southern, resident subspecies E. s. intermedia breaks reed stems and extracts insect larvae (e.g. Stegmann (1948) cited by (Prŷs-Jones 1984), (Matessi et al. 2002; Neto et al. 2013; Orlowski et al. 2013). This behaviour has also been documented in E. s. pyrrhuloides, E. s. witherby and possibly in E. s. stresemanni at Lake Neusiedl (Glutz von Blotzheim and Bauer 1997). The Reed Bunting community at Lake Neusiedl, where birds of different geographic origin mix, could circumvent 
intraspecific competition through the use of different food sources and habitats, which is probably the main driver for beak shape divergence among clusters. This is substantiated by the fact that birds belonging to the local population, during winter, were exclusively encountered in the reed bed of Lake Neusiedl, whereas Reed Buntings that were assigned to clusters 2 and 3 used both habitats, the large reed stand as well as more open areas (Fig. 7b). Also, birds at the salt pan had significantly thinner beaks and lower $\delta^{2} \mathrm{H}$ and $\delta^{13} \mathrm{C}$ values than those caught in the reed. These results show that there is considerable ecological differentiation between the clusters, and indicate higher specialization and local adaption in the local population compared to migrants coming from breeding areas further north.

Adaptations to ecological contexts have also been noted for bird wings, whose morphology and function may be shaped in part by natural or sexual selection (Vanhooydonck et al. 2009). In this study, individuals of cluster 2 had the most rounded wings and again sexual dimorphism was found. The development of short and rounded wings is reported to enhance manoeuvrability (Kaboli et al. 2007), and manoeuvrability and wing loading could correspond with foraging behaviour, microhabitat use, sexual display (Vanhooydonck et al. 2009) and ground predation rates (Burns and Ydenberg 2002; Swaddle and Lockwood 2003; Vanhooydonck et al. 2009). However, in view of sexual differences, the pattern found appears to be more complicated. Related ecomorphological associations, which could involve habitat use or sexual selection (Swaddle and Lockwood 2003), cannot be further discussed at this point, because of a lack of detailed information on effects of environmental and ecological conditions on behavioural properties of northern clusters (2 and 3 ) at their home ranges. The present case study therefore does not enable conclusive interpretation of the mentioned patterns and is calling for a spatial network of studies addressing these exciting topics.

\section{Conclusion}

In conclusion, the present findings provide valuable insights into the phenology, population structure and ecology of the local Reed Bunting community at Lake Neusiedl, providing evidence that the region is not important to the local population alone. A mixture of European populations can be encountered during migration and during winter. This emphasizes the importance of the area on a much bigger geographic scale. Moreover, a variety of habitats is used by northern migrants spending their winter in the region, whereas the local breeding population is more specialized and adapted to the reed belt of the lake. This implies that conservation measures must protect and restore landscape diversity to provide sufficient resources that allow coexistence of populations that mix during the non-breeding season.

Acknowledgements This research was conducted under permissions issued from the Austrian Federal Ministry of Education, Science and Research and the Department for Nature Conservation of the provincial government of Burgenland. We thank the authorities and staff of the Neusiedler See-Seewinkel National Park and the Biological Station Illmitz for logistical support and we thank all helpers for assistance in the field. We are grateful to Yvonne Klaar and Anja Luckner for their excellent support in the stable isotopes laboratory as well as to Alexandre Courtiol for his help with the geographic assignments. The project was funded by the German Ornithologists' Society (DO-G).

Author contributions The study was conceived and designed by BK and CHS. Material preparation, data collection and analysis were performed by BK and CHS and WW commented on previous versions of the manuscript. All authors read and approved the final manuscript.

Funding Open Access funding provided by University of Vienna. The project was funded by the German Ornithologists' Society (research funding, approval 30 November 2017).

Availability of data and material Complete datasets that were used for statistical analysis of this study are available.

Code availability Most applied software was accessible as freeware (ImageJ, TpsUtil, TpsDig2 software package, R) and for the closed source program Adobe Photoshop CS2 version 9.0 a license is available.

\section{Compliance with ethical standards}

Conflict of interest The authors declare that they have no conflict of interest.

Ethics approval All federal permits for data collection and the use of feather material were issued by the Austrian Federal Ministry of Education, Science and Research (BMWFW-66.006/0020-WF/V/3b/2016, approval 23.01.2017) and the Department for Nature Conservation of the provincial government of Burgenland (A4/NN.AB-10055-5-2016, ND-10-05-4226-3-2017). The capture and ringing of birds followed standard protocols and birds were released unharmed on site.

Open Access This article is licensed under a Creative Commons Attribution 4.0 International License, which permits use, sharing, adaptation, distribution and reproduction in any medium or format, as long as you give appropriate credit to the original author(s) and the source, provide a link to the Creative Commons licence, and indicate if changes were made. The images or other third party material in this article are included in the article's Creative Commons licence, unless indicated otherwise in a credit line to the material. If material is not included in the article's Creative Commons licence and your intended use is not permitted by statutory regulation or exceeds the permitted use, you will need to obtain permission directly from the copyright holder. To view a copy of this licence, visit http://creativecommons.org/licenses/by/4.0/. 


\section{References}

Adams DC, Collyer ML, Kaliontzopoulou A (2018) Geomorph: Software for geometric morphometric analyses. $\mathrm{R}$ package version 3.0.6. https://cran.r-project.org/package $=$ geomorph

Arizaga J, Campos F, Alonso D (2006) Variations in wing morphology among subspecies might reflect different migration distances in Bluethroat. Ornis Fennica 83:162-169

Arizaga J, Alonso D, Cortés JA, Eggenhuizen T, Foucher J, Franz D, García J, Koning F, Leconte M, Rguibi H, Valkenburg T, Vera P, Hobson KA (2015) Migratory connectivity in European bird populations: feather stable isotope values correlate with biometrics of breeding and wintering Bluethroats Luscinia svecica. Ardeola 62:255-267. https://doi.org/10.13157/arla.62.2.2015.255

Benassi G, Battisti C, Luiselli L, Boitani L (2009) Area-sensitivity of three reed bed bird species breeding in mediterranean marshland fragments. Wetlands Ecol Manage 17(5):555-564

Benjamini Y, Hochberg Y (1995) Controlling the false discovery rate: a practical and powerful approach to multiple testing. J $\mathrm{R}$ Stat Soc Ser B 57:289-300

BirdLife International (2020) Species factsheet: Aythya nyroca. http://www.birdlife.org. Accessed 08 Oct 2020

Bookstein FL (1991) Morphometric tools for landmark data; geometry and biology. Cambridge University Press, Cambridge

Bookstein FL (1997) Morphometric tools for landmark data: geometry and biology. Cambridge University Press, New York

Brambilla M, Rizzolli F, Pedrini P (2012) The effects of habitat and spatial features of wetland fragments on the abundance of two rallid species with different degrees of habitat specialization. Bird Study 59(3):279-285. https://doi.org/10.1080/00063 657.2012 .666226

Brattström O, Wassenaar LI, Hobsin KA, Åkesson S (2008) Placing butterflies on the map-testing regional geographic resolution of three stable isotopes in Sweden using the monophagus peacock Onachis io. Ecography 31:490-498. https://doi.org/10.11 11/j.2008.0906-7590.05267.x

Briedis M, Beran V, Hahn S, Adamík P (2016) Annual cycle and migration strategies of a habitat specialist, the Tawny Pipit Anthus campestris, revealed by geolocators. J Ornithol 157:619-626. https://doi.org/10.1007/s10336-015-1313-3

Burns JG, Ydenberg RC (2002) The effects of wing loading and gender on the escape flights of least sandpipers (Calidris minutilla) and western sandpipers (Calidris mauri). Behav Ecol Sociobiol $52: 128-136$

Byers C, Olsson U, Curson J (2010) Buntings and sparrows: a guide to the buntings and North American sparrows. Christopher Helm, London

Chabot AA, Hobson KA, Van Wilgenburg SL, McQuat GJ, Lougheed SC (2012) Advances in linking wintering migrant birds to their breeding-ground origins using combined analyses of genetic and stable isotope markers. PLoS ONE 7:e43627. https://doi. org/10.1371/journal.pone.0043627

Courtiol A, Rousset F, Rohwäder M, Soto DX, Lehnert L, Voigt CC, Hobson KA, Wassenaar LI, Kramer-Schadt S (2019) Isoscape computation and inference of spatial origins with mixed models using the R package IsoriX. In: Hobson KA, Wassenaar LI (eds) Tracking animal migration with stable isotopes, 2nd edn. Academic Press, London

Cristol DA, Baker MB, Carbone C (1999) Differential migration revisited: latitudinal segregation by age and sex class. In: Nolan VJ, Ketterson ED, Thompson CF (eds) Current ornithology, vol 15. Academic Press, New York, pp 33-88

Csörgő T et al (2009) Magyar madárvonulási atlasz. Kossuth kiadó, Budapest, pp 635-637
Dawideit BA, Phillimore AB, Laube I, Leisler B, Böhning-Gaese K (2009) Ecomorphological predictors of natal dispersal distances in birds. J Animal Ecol 78:388-395. https://doi.org/10. 1111/j.1365-2656.2008.01504.x

Dvorak M, Ranner A, Berg H-M (1993) Atlas der Brutvögel Österreichs. Ergebnisse der Brutvogelkartierung 1981-1985 der Österreichischen Gesellschaft für Vogelkunde. Umweltbundesamt, Wien

Foster DJ, Podos J, Hendry AP (2008) A geometric morphometric appraisal of beak shape in Darwin's finches. J Evol Biol 21:263-275

Fox J, Weisberg S (2011) An $\{\mathrm{R}\}$ Companion to applied regression, 2nd edition. Sage, Thousand Oaks. http://socserv.socsci.mcmas ter.ca/jfox/Books/Companion

Glutz von Blotzheim U, Bauer KM (1997) Handbuch der Vögel Mitteleuropas. Aula, Wiesbaden

Grant PR (1985) Selection on bill characters in a population of Darwin's finches: Geospiza conirostris on Isla Genovesa, Galapagos. Evolution 39:523-532

Hobson KA (1999) Tracing origins and migration of wildlife using stable isotopes: a review. Oecologia 120:314-326. https://doi. org/10.1007/s004420050865

Hobson KA (2019) Application of isotopic methods to tracking animal movements. In: Hobson KA, Wassenaar LI (eds) Tracking animal migration with stable isotopes, 2nd edn. Academic Press, London

Hobson KA, Wassenaar LI (1999) Stable isotope $\left(\delta D\right.$ and $\left.\delta^{13} C\right)$ are geographic indicators of natal origins of monarch butterflies in eastern North America. Oecologia 120:398-404

Inger R, Bearhop S (2008) Applications of stable isotope analysis to avial ecology. Ibis 150:447-461

IPBES (2019) Summary for policymakers of the global assessment report on biodiversity and ecosystem services of the Intergovernmental Science-Policy Platform on Biodiversity and Ecosystem Services. IPBES Secretariat, Bonn

Jenni LW, Winkler R (1994) Moult and ageing of European Passerines. Academic Press, London

Jenni LW, Winkler R (2007) Alters- und Geschlechtsbestimmung europäischer Singvögel. Schweizerische Vogelwarte Sempbach

Kassambara A (2019) ggpubr: 'ggplot2' Based Publication Ready Plots. R package version 0.2.3. https://CRAN.R-project.org/packa ge $=$ ggpubr

Kaboli M, Aliabadian M, Guillaumet A, Roselaar CS, Prodon R (2007) Ecomorphology of the wheatears (genus Oenanthe). Ibis 149:792-805

Körner C, Farquhar GD, Wong SC (1991) Carbon isotope discrimination by plants follows latitudinal and altitudinal trends. Oecologia $88: 3$

Lajtha K, Marshall JD (1994) Sources of variation in the stable isotopic composition of plants. In: Lajtha K, Michener RH (eds) Stable isotopes in ecology and environmental science. Blackwell, Oxford, pp 1-21

Lockwood R, Swaddle JP, Rayner JMV (1998) Avian wingtip shape reconsidered: wing tip shape indices and morphological adaptions to migration. J Avian Biol 29:273-292

Marra PP, Hobson KA, Holmes RT (1998) Linking winter and summer events in a migratory bird by using stable-carbon isotopes. Science 282:1884-1886. https://doi.org/10.1126/science.282.5395.1884

Matessi G, Griggio M, Pilastro A (2002) The geographical distribution of populations of the large-billed subspecies of reed bunting matches that of its main winter food. Biol J Linn Soc 75:21-26. https://doi.org/10.1046/j.1095-8312.2002.00003.x

Musilová Z, Musil P, Zouhar J, Poláková S (2014) Nest survival in the Reed Bunting Emberiza schoeniclus in fragmented wetland habitats: the effect of nest-site selection. Ornis Fennica 91:138-148 
Neto JM, Gordinho L, Belda EJ, Marin M, Monros JS, Fearon P, Crates R (2013) Phenotypic divergence among west European populations of Reed Bunting Emberiza schoeniclus: the effects of migratory and foraging behaviours. PLoS ONE 8:e63248. https://doi. org/10.1371/journal.pone.0063248

Neto JM, Gordinho LD, Vollot B, Marin M, Monros JS, Newton J (2016) Stable isotopes reveal differences in diet among reed bunting subspecies that vary in bill size. J Avian Biol 48:284-294. https://doi.org/10.1111/jav.01069

Orlowski G, Karg J, Czarnecka J (2013) Substantial contribution of invertebrates to the diet of a winter seed-eater, the reed bunting Emberiza schoeniclus, wintering in a sewage farm in southwestern Poland. Biol J Linn Soc 108:429-433. https://doi.org/10 $.1111 / \mathrm{j} .1095-8312.2012 .02026 . x$

Pasinelli G, Schiegg K (2012) Die Bedeutung kleiner Feuchtgebiete für den Artenschutz: Synthese einer Populationsstudie an der Rohrammer Emberiza schoeniclus. Der Ornithologische Beobachter 109:201-220

Pedersen TL, Hughes S, Qiu X (2017) DensityClust: clustering by fast search and find of density peaks. R package version 0.3 . https:// CRAN.R-project.org/package $=$ densityClust

Procházka P, Van Wilgenburg SL, Neto JM, Yosef R, Hobson KA (2013) Using stable hydrogen isotopes $\left(\delta^{2} \mathrm{H}\right)$ and ring recoveries to trace natal origins in a Eurasian passerine with a migratory divide. J Avian Biol 44:001-010. https://doi.org/10.1111/j.1600048X.2013.00185.X

Prŷs-Jones RP (1984) Migration patterns of the reed bunting, Emberiza schoeniclus schoeniclus, and the dependence of wintering distribution on environmental conditions. Gerfaut 74:15-37

R Core Team (2018) R: A language and environment for statistical computing. R Foundation for Statistical Computing, Vienna, Austria. https://www.R-project.org/

Rohlf FJ (2016a) TpsUtil, Version 1.74. StonyBrook: Department of Ecology and Evolution, State University of New York. http://life. bio.sunysb.edu/morph/index.html

Rohlf FJ (2016b) TpsDig2, Version 2.3. StonyBrook: Department of Ecology and Evolution, State University of New York. http://life. bio.sunysb.edu/morph/index.html

Rubenstein DR, Hobson KA (2004) From birds to butterfies: animal movement patterns and stable isotopes. Trends Ecol Evol 19:256-263

Schneider CA, Rasband WS, Eliceiri KW (2012) NIH Image to ImageJ: 25 years of image analysis. Nat Methods 9:671-675

Staddon PL (2004) Carbon isotopes in functional soil ecology. Trends Ecol Evol 19:148-154
Stegmann B (1948) Functional significance of subspecific characters among Reed Buntings (Emberiza schoeniclus L.). Zoologische Zhurnal 27:241-244

Swaddle JP, Lockwood R (2003) Wingtip shape and flight performance in the European starling Sturnus vulgaris. Ibis 145:457-464

Vanhooydonck B, Herrel A, Gabela A, Podos J (2009) Wing shape variation inthe medium ground finch (Geospiza fortis): an ecomorphological approach. Biol J Linn Soc 98:129-138

Vaurie C (1956) Systematic notes on Palearctic birds. N. 22 Fringilidae: Emberiza schoeniclus. Am Mus Novit 1795:1-13

Vaurie C (1958) Systematic notes on Palearctic birds. N. 33. A second review of Carpodacus puniceus, with a study of its plumages, and a supplementary note on Emberiza schoeniclus. Am Mus Novit 1898:1-10

Veen T, Hjernquist MB, Van Wilgenburg SL, Hobson KA, Folmer E, Font L, Klaassen M (2014) Identifying the African wintering grounds of hybrid flycatchers using a multi-isotope $\left(\delta^{2} \mathrm{H}, \delta^{13} \mathrm{C}\right.$, $\delta^{15} \mathrm{~N}$ ) assignment approach. PLoS ONE 9:e98075. https://doi. org/10.1371/journal.pone.0098075

Voigt CC, Lehnert LS (2018) Tracking of movements of terrestrial mammals using stable isotopes. In: Hobson KA, Wassenaar LI (eds) Tracking animal migration with stable isotopes, 2nd edn. Academic Press, London

Wassenaar LI, Hobson KA (2003) Comparative equilibration and online technique for determination of non-exchangeable hydrogen of keratins for use in animal migration studies. Isot Environ Health Stud 39:211-217

Webster MS, Marra PP (2005) The importance of understanding migratory connectivity and seasonal interactions. In: Greenberg R, Marra PP (eds) Birds of two worlds. John Hopkins University Press, Baltimore

Webster MS, Marra PP, Haig SM, Bensch S, Holmes RT (2002) Links between worlds: unraveling migratory connectivity. Trends Ecol Evol 17:76-83

Woodworth BK et al (2016) Differential migration and the link between winter latitude, timing of migration, and breeding in a songbird. Oecologia 181:413-422. https://doi.org/10.1007/s0044 2-015-3527-8

Zelditch ML, Swiderski DL, Sheets HD, Fink WL (2004) Geometric morphometrics for biologists: a primer. Elsevier, London

Publisher's Note Springer Nature remains neutral with regard to jurisdictional claims in published maps and institutional affiliations.

\section{Authors and Affiliations}

\section{Barbara Kofler $^{1}(1) \cdot$ Wolfgang Wanek ${ }^{2}$. Christian C. Voigt ${ }^{3} \cdot$ Christian H. Schulze $^{4}$}

1 Department of Behavioral \& Cognitive Biology, University of Vienna, Althanstrasse 14, 1090 Vienna, Austria

2 Division of Terrestrial Ecosystem Research, Department of Microbiology and Ecosystem Science, Althanstrasse 14, 1090 Vienna, Austria
3 Leibniz Institute for Zoo and Wildlife Research, Berlin, Germany

4 Department of Botany and Biodiversity Research, University of Vienna, Rennweg 14, 1030 Vienna, Austria 